\title{
Architecture of a pulmonary thrombus removed during embolectomy in a patient with acute pulmonary embolism
}

\author{
Anetta Undas, MD, PhD, ${ }^{a}$ Ewa Stępień, PhD, ${ }^{b}$ Paweł Rudziński, MD, PhD, ${ }^{a}$ and Jerzy Sadowski, MD, PhD, ${ }^{a}$ \\ Cracow, Poland
}

To our knowledge, thrombus structure in patients with pulmonary embolism (PE) has not been analyzed with scanning electron microscopy (SEM). We hypothesized that particular features of a pulmonary embolus explain in part a failure of thromboprophylaxis. Microscopic examination of a fresh thromboembolus from a pulmonary artery obtained at autopsy indicated that its structure is composed of layers of platelets and fibrin alternating with layers of erythrocytes. ${ }^{1}$ Fibrin clot architecture largely determines the fibrinolysis rate because a compact clot structure impairs the transport of endogenous proteins involved in fibrinolysis through fibrin networks. ${ }^{2}$ Here we describe the structure of the embolic material obtained from a patient with PE.

\section{CLINICAL SUMMARY}

A 46-year-old nonsmoking man (body mass index, 34.6 $\mathrm{kg} / \mathrm{m}^{2}$ ) with no history of thrombosis was admitted for submassive PE. Nine days earlier, the patient experienced stable L1-L2 vertebral fractures after falling from a height. He was treated with strict bed rest, a lumbar corset, and a Jewett extension brace. Despite thromboprophylaxis (2850 U of nadroparin administered subcutaneously twice daily), progressive dyspnea developed on the fifth day, with no leg edema or pain. Contrast-enhanced computed tomographic analysis showed a large embolus at the bifurcation of the main pulmonary trunk (Figure 1), A. Ultrasonographic examination demonstrated a partly recanalized thrombus obstructing the left popliteal vein. No lytic therapy was administered. For fear of hemorrhagic complications, the patient, who was in a worsening clinical condition, underwent open embolectomy with cardiopulmonary bypass under normothermic conditions. After opening of the pulmonary trunk, a 7-cmlong embolus was removed. Postoperatively, unfractionated heparin was administered, followed by oral anticoagulation.

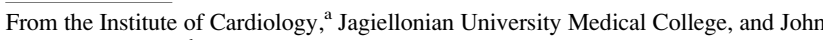
Paul II Hospital, ${ }^{\text {b }}$ Cracow, Poland

Supported by a grant of Jagiellonian University Medical College, number K/ZDS/ 000565 (to A.U.).

Disclosures: None.

Received for publication May 11, 2009; revisions received June 10, 2009; accepted for publication July 16, 2009; available ahead of print Aug 19, 2009.

Address for reprints: Anetta Undas, MD, PhD, Institute of Cardiology, Jagiellonian University School of Medicine, 80 Pradnicka St, 31-202 Cracow, Poland (E-mail: mmundas@cyf-kr.edu.pl).

J Thorac Cardiovasc Surg 2010;140:e40-1

$0022-5223 / \$ 36.00$

Copyright (c) 2010 by The American Association for Thoracic Surgery doi: $10.1016 /$ j.jtcvs.2009.07.038
}
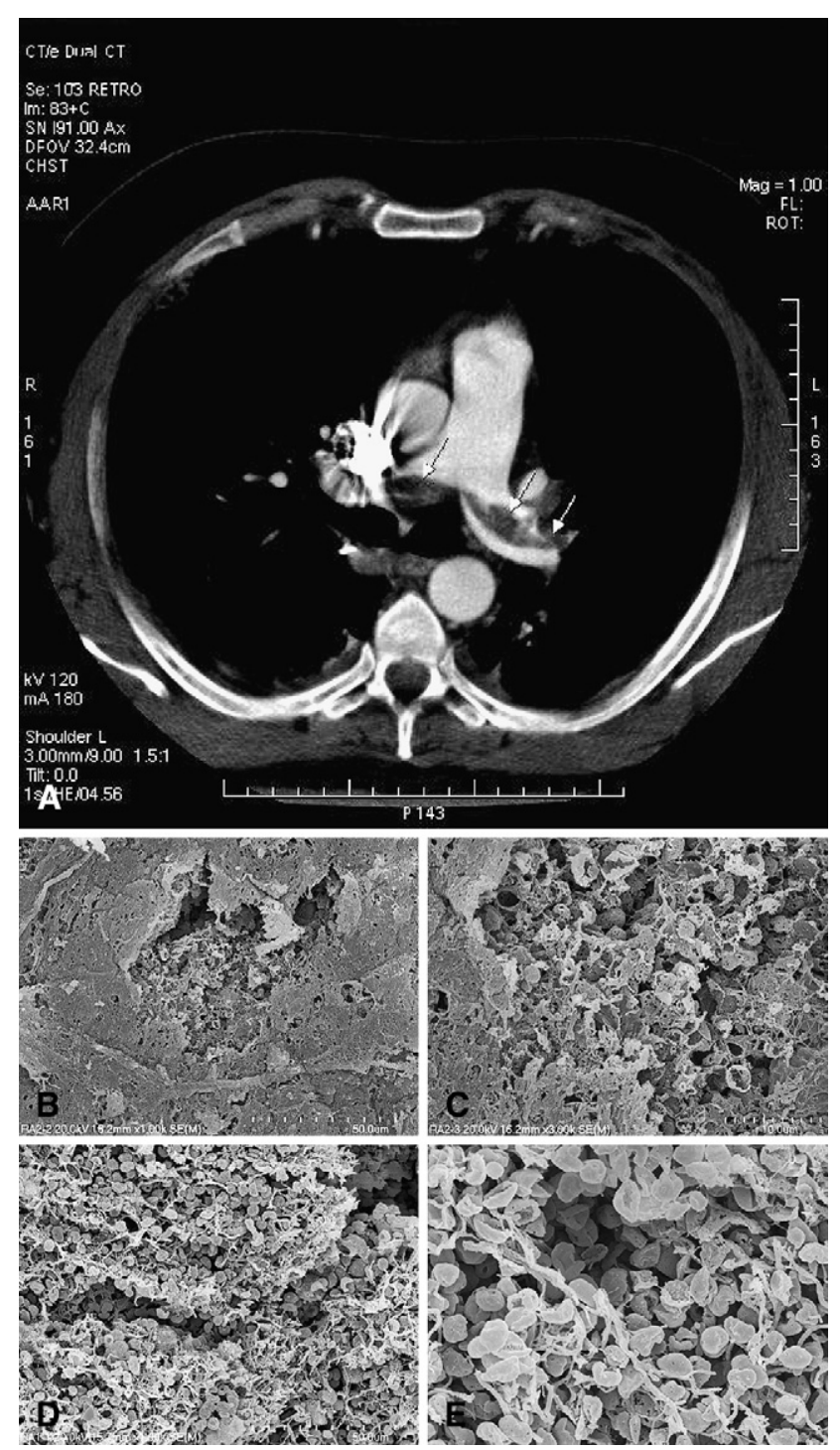

FIGURE 1. Computed tomographic analysis of the chest showing a large thrombus in the pulmonary arteries (A). Representative scanning electron microscopic images showing the central part of the removed thrombus (B and $\mathrm{C}$ ) and its periphery extending into the left pulmonary artery (D and E). B and D, Low magnification, $1000 \times$; C and E, high magnification, $5000 \times$.

A 1-year follow-up was uneventful. Thrombophilia screening (Factor V Leiden mutation, prothrombin 20210A variant, protein $\mathrm{C}$ activity, antithrombin activity, free protein $\mathrm{S}$ concentration, anti- $\beta_{2}$-glycoprotein I and anticardiolipin antibodies, and lupus anticoagulant) yielded normal results. 
The embolus, removed 4 days from symptom onset, was evaluated by using SEM, as previously described. ${ }^{3}$ Briefly, after washing, the thrombus was fixed by means of permeation with $2.5 \%$ glutaraldehyde and then treated with alcohol, dehydrated, gold coated, and photographed digitally with a Hitachi S-4700 SEM (Hitachi, Tokyo, Japan).

The SEM images revealed that the inner parts of the removed thrombus (Figure 1, $B$ and $C$ ) are formed with tightly packed, thick fibrin fibers resembling a solid mass; however, in the very center there was cellular debris derived predominantly from erythrocytes. At the periphery of the clot (Figure 1, $D$ and $E$ ), a large amount of red blood cells embedded in a relatively thin fibrin network with low amounts of platelet aggregates was visualized. No layered structure of the embolus was observed.

\section{DISCUSSION}

Contrary to the available scarce morphologic data, ${ }^{1}$ we did not observe a layered thrombus structure. Compared with thrombi removed from a coronary artery of patients with acute myocardial infarction, which were fibrin rich with erythrocytes and almost no platelets, ${ }^{4}$ the pulmonary thrombus was much more organized and contained relatively more fibrin and fewer red blood cells, which were present mainly in peripheral segments of the clot. The more compact the fibrin fiber structure, the less susceptible to lysis, ${ }^{2}$ and not surprisingly, such thrombi (Figure 1) are resistant to endogenous fibrinolysis.

Thrombi from patients not receiving thromboprophylaxis are likely even more dense, as seen at higher thrombin concentrations. ${ }^{5}$ Our findings might also help explain why fibrinolytic therapy might fail to rescue patients with large pulmonary thrombi and comprised cardiopulmonary function, in whom embolectomy could be more effective.

\section{References}

1. Wagenvoort CA. Pathology of pulmonary thromboembolism. Chest. 1995; 107(suppl):10S-7S.

2. Scott EM, Ariëns RAS, Grant PJ. Genetic and environmental determinants of fibrin structure and function. Relevance to clinical disease. Arterioscler Thromb Vasc Biol. 2004;24:1558-66.

3. Undas A, Szuldrzynski K, Stepien E, Zalewski J, Godlewski J, Pasowicz M, et al. Reduced clot permeability and susceptibility to lysis in patients with acute coronary syndrome: effects of inflammation and oxidative stress. Atherosclerosis. 2007;196: $551-8$

4. Beygui F, Collet JP, Nagaswami C, Weisel JW, Montalescot G. Architecture of in tracoronary thrombi in ST-elevation acute myocardial infarction. Circulation. 2006;113:e21-3.

5. Wolberg AS. Thrombin generation and fibrin clot structure. Blood Rev. 2007;21: 131-42.

\title{
Pulmonary thromboendarterectomy in Klippel-Trénaunay syndrome
}

\author{
Jonathan N. Johnson, MD, ${ }^{\text {a }}$ David J. Driscoll, MD, ${ }^{\text {a }}$ and Christopher G. A. McGregor, MB, FRCS, MD \\ (Hons), ${ }^{\mathrm{b}}$ Rochester, Minn
}

Chronic thromboembolic pulmonary hypertension (CTEPH) occurs in $4 \%$ of patients with pulmonary embolism (PE). ${ }^{1}$ Untreated, the likelihood of survival is poor. Klippel-Trénaunay syndrome (KTS) is a rare complex vascular malformation that typically includes the triad of capillary vascular malformation (port-wine stain), venous malformation(s), and soft tissue or bony hypertrophy. ${ }^{2}$

\footnotetext{
From the Department of Pediatrics, Division of Pediatric Cardiology, ${ }^{\mathrm{a}}$ and Department of Surgery, Division of Cardiothoracic Surgery, ${ }^{\mathrm{b}}$ Mayo Clinic College of Medicine, Rochester, Minn

Disclosures: None.

Received for publication March 4, 2010; accepted for publication March 20, 2010; available ahead of print May 3, 2010.

Address for reprints: David J. Driscoll, MD, Department of Pediatrics, Division of Pediatric Cardiology, Mayo Clinic College of Medicine, Rochester, Minnesota, Mayo Clinic, Gonda 6, 200 First Street SW, Rochester, MN 55905 (E-mail: driscoll. david@mayo.edu).

J Thorac Cardiovasc Surg 2010;140:e41-3

0022-5223/\$36.00

Copyright (c) 2010 by The American Association for Thoracic Surgery

doi:10.1016/j.jtcvs.2010.03.030
}

Patients with KTS are at increased risk for peripheral venous thrombosis and pulmonary emboli. ${ }^{3}$ When medical management of PE and CTEPH fails, pulmonary thromboendarterectomy (PTE) is an important, potentially lifesaving therapy. ${ }^{1}$

\section{CLINICAL SUMMARY}

Three patients with KTS ( 2 women aged 19 and 46 years and 1 man aged 26 years, Table 1) underwent PTE. The patients had symptoms for an average of 9.6 months (range, 3-19 months) before surgery. Patient 2 had a diagnosis of deep vein thrombosis before the CTEPH diagnosis. Patient 1 previously had a right arm amputation for complications of vascular malformation. No patient had a clotting disorder. Each patient had all 3 manifestations of KTS, including capillary malformations, venous malformations, and soft tissue hypertrophy.

A single surgeon performed all operations. The surgical technique used was described by Jamieson and colleagues. ${ }^{1}$ 